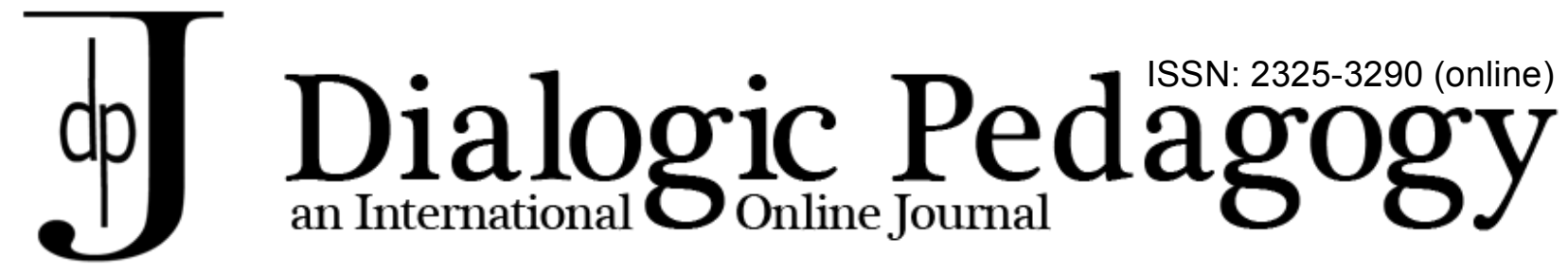

\title{
Dialogic approaches to the study of subjectivity
}

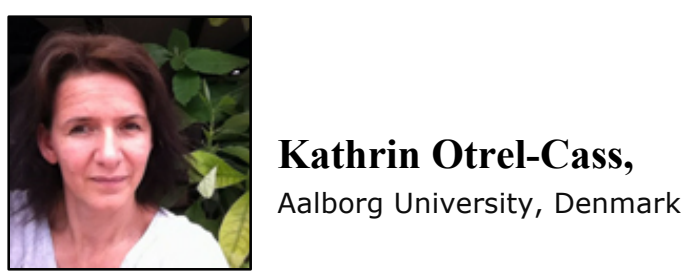

\section{Abstract}

Book review: Sullivan, P. (2012). Qualitative Data Analysis: Using a dialogic approach. Los Angeles: SAGE Publications Ltd. ISBN 978-1-84920-609-9

Paul Sullivan prepared his book Qualitative Data Analysis: Using a dialogic approach for social science researchers who are interested in qualitative data analysis and who have an interest in a dialogical approach to data analysis. The book is in essence concerned with the nature of subjectivity and how to make sense of it. Sullivan explains that from a dialogic position subjectivity can be seen as a conscious activity where the researcher anticipates the ideas and judgments expressed through dialogue from others by drawing on "a network of history, tradition and power" (p.44). Through this Sullivan (referring to Gee, 2005) emphasizes the importance for the qualitative researcher to view discourse as language in action. Sullivan writes that the dialogical approach 'provides tools for the methodological analysis of subjectivity, being theorized as the changing and responding to others' ( $p .4)$ and that by using Bakhtin's ideas discourse can be viewed as "embodied subjectivity" (p.44) and the conscious act of anticipation and judgment.

Sullivan declares at the very beginning clearly his position and particular interest in Michael Bakhtin's dialogic ideas and how they shape qualitative methodologies. However, Sullivan states that Bakhtin's ideas can be at times difficult to use in qualitative methodology and that the aim of this book to give 'dialogue' a methodology and place of its own within the qualitative paradigm. He writes that he sees three key contributions coming from Bakhtin's work: First, the 'existential existence on a needy self " (p.14), which refers to the notion that both the researcher as well as the participant bring attitudes of trust and suspicion to the interpretation of text material and with this, Bakhtin is positioning the participant as being a valid knower, capable of interpreting his own data but also that there are more interpretations to the same experience and that a dialogic approach to analysis uncovers not the truth but rather the possibilities of truths. Second, Bakhtin's 'emphasis on 'truth' as 'pravda' in a dialogical approach' (p.15) which refers to someone's vested interest in their belief and that beliefs can be so strong that they become truth and be embodied by a person. Third, the idea that 'otherness and mystery can be built into the fabric of talk' emphasizes Bakhtin's discussion about anticipated responses delineating boundaries between the self and other.

I enjoyed reading Sullivan's description of dialogic analysis because he contrasts its philosophical and methodological underpinnings with other methods of discourse analysis. But more than that Sullivan 
cross-examines through this the dialogic approach to make an argument for it to be used in the analysis of discourse. I was drawn to Paul Sullivan's book because he starts by reminding the reader of the importance of the philosophical framework a researcher needs to uncover truth and its interconnectedness with research methods and analysis procedures. All researchers interested in dialogue and discourse are eager to collect data in the search for answers but but not seldom overlook how much can be gained by finding out how different theories of knowledge shape research findings. Sullivan reminds us that 'by looking at the methodological 'practices', we can more clearly delineate the contours of a method' (p.6). He is making this point throughout the book by discussing how other methodological positions such as grounded theory, discourse analyses, phenomenological analyses or narrative analyses shape the nature of meaning making of language in action and contrasts it with the contribution a dialogical approach can make.

I found also that Sullivan exemplifies his approach to dialogism by applying it to his own writing in this book, drawing attention to the conflicts, judgments and interpretative activities in the use, capture and analysis of language. He practices dialogism by interacting with the ideas he draws on and reviewing them critically. When he provides the reader with pragmatic and concrete examples, he uses them to explore theoretical aspects that shape the data analysis, echoing his appreciation for Bakhtin's focus on practical and usable theories. Sullivan spends time drawing attention to different analytical methods including grounded theory, discourse analysis, narrative analysis and phenomenological analysis being mindful of the various traditions and their analytical elements they bring to the analysis of dialogue. This is important because it creates the argument why a dialogic approach to data analysis is different but also how it is influenced by those traditions and where it can add new insights into the analysis of discourse.

The book allows the readers to examine their own positions on the nature of dialogue, their struggles to identify intimate, emotional encounters in language and shows ways to uncover transformations. Sullivan achieves this by sharing his own struggles and challenges for instance by reflecting "...I was unsure what the overview was or what the specific questions would be" (p.83), when he is writing on the presentation of a summary of the overview of the analysis. Sullivan encourages his audience as well to develop their own voice through the joint creation between theory and data.

Sullivan is not uncritical about the dialogical approach to qualitative analysis. While he draws attention to its strengths he also explains that it may be used in addition to other approaches to gain new and different insights. He describes that the dialogic approach has optimistic views of conscious awareness and potential flaws in how power relations are perceived (p.62). However he reflects also to say that its particular suitability lies in making sense of subjectivity, lived experiences and authorship.

At the end of the book Sullivan reflects on theory and applications and his proposed ways forward. He also reminds the reader to take note of his position and the theoretical ideas that have influenced his thinking. He exemplifies here again Bakhtin's ideas he referred to at the beginning of the book that 'ideas are lived rather than abstract and full of personal values and judgments' (p.5). I appreciated the book's pragmatic yet highly theoretical and critical approach to the topic. I believe this book can be very useful for social science researchers who are interested in the qualitative analysis of dialogue. Sullivan skillfully provides the reader with tools - both ontological and pragmatic. He uses an aesthetic approach to discourse that emphasizes how 'discourse can shapes selves and how selves can respond to this shaping' (p.43) and builds on Bakhtin's ideas of how identity is shaped by both the anticipation of what is to be expected and how this shapes the 'authoring of our own identity' (p.3).

Dialogic Pedagogy: An International Online Journal | http://dpj.pitt.edu 


\section{(cc) EY}

Articles in this journal are licensed under a Creative Commons Attribution 3.0 United States License.

\section{UILIS D-Sente}

This journal is published by the University Library System, University of Pittsburgh as part of its D-Scribe Digital Publishing Program and is cosponsored by the University of Pittsburgh Press. 